\title{
Striding Both Worlds: Witi Ihimaera and New Zealand's Literary Traditions
}

By Melissa Kennedy. Rodophi, Amsterdam, New York, 2011.

ISBN 9042033576, 9789042033573

Reviewed by Therese Crocker

Witi Ihimaera has been a dominant force in New Zealand literature for four decades. In Striding Both Worlds Melissa Kennedy presents a study of the published works of Ihimeara and considers his place in the New Zealand literary landscape. The image evoked from the title, of Ihimaera with a foothold in both Māori and Pākehā literary traditions, immediately alerts the reader to a potentially broader reading of Ihimaera's work than may previously have been explored. Striding Both Worlds is a reworking of Kennedy's 2007 doctoral dissertation: 'Striding Both Worlds: Cross-Cultural Influence in the Work of Witi Ihimaera', a collaboration between Université de Bourgogne, Dijion and the University of Canterbury, Christchurch.

Witi Ihimaera's contribution to Māori literature is immense. His prolific writing record makes him a worthy subject of such a study, with 30 published works (including two coedited works) considered in this study, spanning a 37 year period. At the time of its publication in 1973 the novel Tangi presented insight and detail of Māori life that had not previously been the subject of a first-person narrative. In the protagonist Tama, Ihimaera captured a fictional voice illustrating the changing nature of the Māori world. In the novel Tama walks a line, having a foothold in both the world of Māori tradition, of rural village life, protocols of the tangihana (or funeral rites) and the Pākehā world of the hustle and expectations of urban living. As Tama steps further into the Pākehā world he recognizes that he is managing to 'stride both worlds.' ${ }^{1}$ And so it was that Ihimaera, as a new Māori author became regarded as a conduit, a go-between, presenting a predominantly rural Māori world to an increasingly urban Pākehā one. Although the works of the 1970s, particularly Pounamu, pounamu, Tangi and Whanau, were dominated by the romantic pastoral mode channelling 'unabashed lyrical evocations of a world that once was', Ihimaera later reflected that even at the time of writing they were seriously out of step 'with the reality of the times.' ${ }^{2}$ Māori life was becoming more urban, more fractured and more political. Ihimaera's writing came to reflect these shifts in works such as The Matriarch.

It is easy to see Ihimaera's contribution as introducing and revealing the Māori world in the written English form. Indeed the fact that Ihimaera's first published novel, Tangi (1973) was the first published novel by a Māori writer compels us to consider Ihimaera in that context. Through Ihimaera's work, Māori storytelling traditions, allegory, myth and political concerns were made increasingly accessible to readers of English. However, Kennedy urges a consideration of Ihimaera's work that goes beyond this primary reading. She points out that there is much more to the Ihimaera's writing, and in doing so effectively illustrates the two worlds of the title. While it is easy to focus solely on the 'Māori' aspects of the writing, a reader does so at the expense of recognizing how it fits with national and international themes, styles and approaches. There is the obvious transition from the pastoral to the political, as outlined in an earlier study of Ihimaera, Witi Ihimaera: A Changing Vision, by Umelo Ojinmah. ${ }^{3}$ Although Ihimaera's work has broadened since the publication of that study.

Kennedy attempts to see Ihimaera's work in the context of the wider Pākehā cultural nationalism of writers such as Allen Curnow and Frank Sargeson, where themes of hardship, mateship and working-class values are dominant (p.17). Kennedy traverses the broad scope of Ihimaera's work to draw out wider references. These include opera, in Waituhi: The Life of 
the Village (1984) and The Matriarch (1986), references to science-fiction and fantasy in Sky Dancer (2003) and gay identity in Nights in the Gardens of Spain (1995). Kennedy cautions against the 'over-emphasis on the Māori aspects of Ihimaera's work at the expense of literary or operatic influences and similarities disallows fiction its inherent ambiguities' (p.58). In other words, a narrow reading of Ihimaera's work not only denies him the opportunity to express himself outside of a bicultural framework - in what he called his more personal or 'selfish' writing - but also potentially limits the experience of the reader (p.46). Ihimaera himself identifies two different relationships Māori have with contemporary society: 'The first is an issue of Māori rights' and is concerned with colonization and its impact. The second relationship is the 'negotiations between Māori and Pakeha new Zealanders of their shared cultural inheritance' (p.48).

Kennedy emphasizes the multiple voices and readings of Ihimaera's 'literary imaginary' noting the inspiration of 'Māori cultural concepts and non-traditional genres including science-fiction, ballet, opera, and screenplays' (p.212). Ihimaeara's writing easily extends from indigeneity to internationalism. This wide interpretation is evidenced by the international reaction to the film interpretation of Whale Rider, which resulted in an international edition of the book being published in 2003. Worldwide audiences responded to the determination of the young heroine, Paikea, to overcome adversity. Ihimaera drew attention to these aspects in the international promotion of the film (p.208).

The 'both worlds' of the title can often be read simultaneously, rather than as binary opposites. According to Kennedy with emphasis on 'plurality and the fluidity of boundaries between self and other, Striding Both Worlds, advocates the non-resolution of cultural and literary interpretation' (p.xix). Kennedy concludes that Ihimaera recycles rewrites and comments on Māori culture and literature in different ways to suit different audiences, referencing Māori sovereignty, biculturalism, all-inclusive nationalism, and globalization. Kennedy has considered her subject with skill and considered argument. She advocates that Ihimaera's work and contribution be considered broadly and 'read from both directions' (p.59).

\footnotetext{
${ }^{1}$ Witi Ihimaera, Tangi, London, 1973, p.78.

${ }^{2}$ Witi Ihimaera, 'Maori Life and Literature: A Sensory Perception', Turnbull Library Record, 15, 1, (1982), p.50.

${ }^{3}$ Umelo Ojinmah, Witi Ihimaera: A Changing Vision, Dunedin, 1993.
} 